\title{
Conceitos de modelagem e de redes neurais artificiais em aproximações de funções
}

\author{
Cansian, A. B. M. ${ }^{1}$; Souza, A. P. T. ${ }^{2}$; Costa, A. O. S. ${ }^{3}$; Costa Jr, E. F. C. ${ }^{3}$ \\ 1 Graduação em Engenharia Química, Universidade Federal do Espírito Santo, Alegre, ES, Brasil \\ 2 Docente na Escola Estadual de Ensino Fundamental e Médio Aristeu Aguiar, Alegre, ES, Brasil \\ 3 Programa de Pós-Graduação em Engenharia Química, Curso de Graduação em Engenharia Química \\ Departamento de Engenharia Rural, CCA, Universidade Federal do Espírito Santo - UFES, Alegre , ES, Brasil
}

\begin{abstract}
Resumo
Uma análise do perfil dos alunos que concluem o ensino médio nas escolas brasileiras, em especial as escolas públicas, indica uma base matemática deficiente. Além da dificuldade de aprendizado, a literatura reporta, como uma das causas desta deficiência, o pouco interesse nesta disciplina, muitas vezes motivado pelo desconhecimento da aplicação da mesma. O uso da Modelagem Matemática como maneira de incentivar o interesse no aprendizado da Matemática é apontado por diversos autores. Este trabalho apresenta a ideia geral de um do projeto de pesquisa em andamento que tem como objetivo a aplicação de redes neurais artificiais em problemas diversos para contextualizar didaticamente os princípios de modelagem matemática. Especificamente, objetiva-se que o grupo de ensino médio e da graduação domine a técnica de Modelagem Empírica por Redes Neurais Artificiais. Por fim, fazer uma discussão da análise de dados e modelos encontrados em bibliografias. Os resultados do primeiro trimestre de execução consistem na apresentação dos conceitos de erro experimental, modelo matemático, erros do modelo, além do coeficiente de determinação empregando-se regressões lineares a partir de dados coletados em experimentos de laboratório.
\end{abstract}

Keywords (Palavras chaves): Matemática, modelagem empírica, erros experimentais.

\section{Introdução}

A trajetória escolar de um aluno é compreendida através das experiências de sua origem, das pessoas e situações que viveu e conviveu, e não do indivíduo sozinho. Analisando as gerações passadas, observa-se que entre as mulheres havia menor representação nas áreas de exatas [1].

No contexto atual, aproximadamente $10 \%$ dos alunos de escola pública no Brasil aprendem, realmente, matemática. A maior defasagem no ensino médio é em matemática, e estudantes com maior defasagem apresentam rendimentos baixos [2].

O emprego da Modelagem Matemática na educação brasileira já vem sendo desenvolvido há bastante tempo, mas ainda se discute como utilizar esta ferramenta para o estímulo ao aprendizado de Matemática. Neste contexto, o presente trabalho apresenta ideia central do projeto de pesquisa "Princípios de Modelagem Matemática pela Aplicação de Redes Neurais Artificiais" aprovado na Chamada N ${ }^{\circ}$ 18/2013 MCTI/CNPq/SPM-PR/Petrobras - Meninas e Jovens Fazendo Ciências Exatas, Engenharias e Computação. Este projeto está sendo executado por professores e discente do curso de Engenharia Química da UFES, em conjunto com professora e alunas de ensino médio de uma escola pública de Alegre.

A análise de regressão atua nas informações de um conjunto de dados, e expressa o relacionamento que existe entre as variáveis do processo por meio de um modelo. Esse modelo é utilizado para descrever, estimar, controlar e predizer situações ou problemas [3]. Os programas que utilizam as redes neurais estão baseados nessa análise, e podem ser organizados de formas diferentes, conforme o nível de dificuldade para uma solução.

\section{Materiais e Métodos}

Para a introdução do trabalho com as alunas de ensino médio foram trabalhos os conceitos de variáveis, funções, modelo matemático e erros de medição. Tais conceitos são a base para explicação de modelos matemáticos empíricos e seus significados práticos. Foi realizado um experimento em laboratório com as alunas onde se mediram diferentes valores de massa e volume de água. Objetivou-se observar o comportamento das variáveis massa e volume em um gráfico, assim como os erros nas medidas. Após a coleta de dados, os mesmos foram aproximados no modelo empírico mais simples: regressão linear simples. Além deste modelo, gerou-se outro modelo empírico linear que agrega uma informação física do problema (definição de densidade).

\section{Resultados e Discussão}

A partir de estudos em grupo as alunas se integraram de significados físicos e práticos dos conceitos abordados. Dadas as constantes $a$ e $b$ e uma variável $x$, as funções lineares apresentam-se da forma: [4]

$f(x)=a x+b$ 
A aproximação por regressão linear simples é eficiente na descrição de problemas nos quais uma variável dependente apresenta comportamento linear como função de uma única variável dependente. Para a introdução deste conceito, as alunas de ensino médio coletaram, em laboratório, os dados de massa e volume de água em uma proveta para diversas amostras. A balança foi tarada para que apresentasse somente o valor da massa da água e não da proveta. Foi considerado o volume como variável independente e a massa como variável dependente. O resultado da regressão linear feita no Excel é:

$y=0,9945 x-1,274$

A Equação (2) é puramente empírica e as alunas do ensino médio foram estimuladas a discutirem sobre o significado desta equação à luz do conceito de densidade. A partir deste conceito, o valor do termo $b$ deveria ser nulo e por meio de discussão orientada, o grupo chegou à conclusão de que os erros de medida nas variáveis massa e volume (em especial o volume) possibilitaram a obtenção de um valor de $b$ diferente de zero. A partir desta conclusão, a regressão foi refeita com a restrição de que 0 valor de $b$ fosse nulo, obtendo-se:

$y=0,9845 x$

$\mathrm{Na}$ tabela 1 estão apresentados os dados experimentais assim como a massa calculada a partir dos modelos das Equações (2) e (3).

\begin{tabular}{cccc}
\multicolumn{4}{c}{ Tabela 1 : Dados de volume e massa. } \\
\hline $\begin{array}{c}\text { Volume } \\
(\mathrm{mL})\end{array}$ & Massa $(\mathrm{g})$ & $\begin{array}{c}\text { Massa } \\
\text { calculada } \\
\text { por }(2)(\mathrm{g})\end{array}$ & $\begin{array}{c}\text { Massa } \\
\text { calculada } \\
\text { por }(3)(\mathrm{g})\end{array}$ \\
\hline 37 & 34,535 & 35,523 & 36,427 \\
\hline 53 & 52,051 & 51,435 & 52,179 \\
\hline 68 & 66,267 & 66,352 & 66,946 \\
\hline 87 & 84,944 & 85,248 & 85,652 \\
\hline 102 & 100,919 & 100,165 & 100,419 \\
\hline 117 & 115,562 & 115,083 & 115,187 \\
\hline 127 & 124,867 & 125,028 & 125,032 \\
\hline 136 & 135,081 & 133,978 & 133,892 \\
\hline 153 & 150,037 & 150,885 & 150,629 \\
\hline 166 & 163,517 & 163,813 & 163,427 \\
\hline 172 & 169,487 & 169,780 & 169,334 \\
\hline
\end{tabular}

Os valores para o coeficiente de determinação foram $\mathrm{R}^{2}=0,9998$ para Equação (2) e $\mathrm{R}^{2}=0,9997$ para a Equação (3). Comparando o desempenho dos dois modelos, o grupo pôde verificar que, para as duas equações, os maiores erros são obtidos para os menores valores de volume, que contêm os maiores erros relativos, já que os dados medidos apresentam apenas dois algarismos significativos. Os resultados apresentados também permitem a conclusão de um modelo empírico com mais parâmetros apresenta erros menores e um maior coeficiente de determinação. Entretanto, mais parâmetros não significam necessariamente uma melhor descrição do processo estudado.

\section{Conclusão}

Os resultados obtidos no primeiro trimestre de execução do projeto de pesquisa confirmam a informação da literatura de que a modelagem matemática pode ser empregada como um estímulo ao aprendizado de Matemática. Foi possível, por meio de regressões lineares empregando dados de um experimento de baixo custo, o desenvolvimento dos conceitos básicos de modelagem empírica. Ressalta-se a preocupação com os níveis da linguagem empregada e dos conceitos apresentados para que as alunas de ensino médio pudessem realizar as atividades propostas e não agirem como expectadoras. Como continuação deste trabalho, serão empregados dados com comportamento não linear para a introdução do conceito de funções não lineares e da técnica de modelagem não linear baseada em redes neurais.

\section{Agradecimentos}

Os autores agradecem ao CNPq pelo apoio financeiro, processo no 420147/2013-6, e pela bolsa de produtividade DTI e à FAPES pela bolsa de pesquisador capixaba.

\section{Referências}

[1] ÁVILA, R.C.; PORTES, E. A tríplice jornada de mulheres pobres na universidade pública: trabalho doméstico, trabalho remunerado e estudos, 2012. Disponível

em:

<https://periodicos.ufsc.br/index.php/ref/article/view/276

63> acesso em: 11 de maio de 2014.

[2] Desempenho dos alunos do ensino médio ficou abaixo do nível adequado. Disponível em <http://memoria.ebc.com.br/agenciabrasil/noticia/201303-06/desempenho-dos-alunos-do-ensino-medio-ficouabaixo-do-nivel-adequado-revela-pesquisa>. Acesso em: 15 de maio de 2014.

[3] WERKEMA, M.C.C.; AGUIAR, S. Análise de regressão: como entender o relacionamento entre as várias variáveis de um processo. Belo Horizonte, MG: Fundação Christiano Ottoni, Escola de Engenharia da UFMG, 1996.

[4] DANTE, L.R., Matemática, 1aㅡ ed., São Paulo, Ática, 2005. 